\title{
Intensity of Social Network Use by Involvement: A Study of Young Chinese Users
}

\author{
Choo-Hui Park ${ }^{1} \&$ Yong June Kim ${ }^{2}$ \\ ${ }^{1}$ Keimyung University, Daegu, South Korea \\ ${ }^{2}$ Sungkyunkwan University, Seoul, South Korea \\ Correspondence: Choo-Hui Park, Keimyung University, Daegu, South Korea. Tel: 82-53-580-6757. E-mail: \\ shineforeverjp@gmail.com
}

Received: October 31, 2012 Accepted: January 24, 2013 Online Published: February 20, 2013

doi:10.5539/ijbm.v8n6p22

URL: http://dx.doi.org/10.5539/ijbm.v8n6p22

This research is supported by the National Research Foundation of Korea (NRF-2010-413-B00029)

\begin{abstract}
This research focuses on the use of social network sites (SNS) among young Chinese users. There are two objectives of this study. First, the paper examines the characteristics and current situations of SNS in China. The second is to examine the relationship between the types of involvement and the intensity of SNS use. This study uses data from 200 samples, mostly young Chinese users in Beijing, China. Factor analysis suggests four factors: personal involvement in usefulness and usage, physical involvement in trust, and situational involvement in relationships. The total variance explained by all four factors is 67.82 percent. Personal involvement on usefulness accounts for most (33.12\%) of the explained variance, followed by physical involvement in trust (13.47\%). In general, correlation results show that there are significant relationships between the intensity to use SNS and all types of involvement. Personal involvement in usefulness shows a very strong relationship with the intensity of SNS use(cor $=.93)$. Through regression, the result suggests that only personal involvement in usefulness and physical involvement in trust are in the model, with a value of 88.5 percent for $\mathrm{R}^{2}$, which significantly explains the intensity of SNS use. The results from this study provide insightful information on how different types of involvement can influence users' intensity of SNS use. The mostly frequently used social network sites among participants for this study are Renren, QQ(Qzone) and Sina Space.
\end{abstract}

Keywords: social network sites, involvement, adoption, intensity of use, young Chinese people

\section{Introduction}

Social Networking Sites (SNS) have significantly expanded as a communication tool since 2006. Nowadays, the importance of SNS has become a major issue within society, as well as a significant study topic for many researchers. Social network sites integrate digital communication; in addition, the most important characteristic of SNS is that they enable users to make their social networks visible and build connections among individuals (Shi, Lee, Cheung \& Chen, 2010). SNS such as Facebook, Myspace, LinkedIn in the US, Cyworld in Korea, Friendster in Asia, Hi5 in Spanish-speaking countries, and QQ, RenRen, Kaixin001 in China are the most frequently used SNS among people worldwide (Yanqiu, 2011). The 2008 comScore survey regarding global SNS usage showed that Asia has been a part of the world where this phenomenon is flourishing (Lin, Chiu \& Lim, 2011). China has its own versions of Facebook and their social networking landscape is much more diverse in terms of users and purposes. Many of Chinese people are motivated to be involved in social network sites for many different reasons, such as connecting with friends and family, socializing with new friends, and accessing information, among many others. China has the largest number of Internet users around the world (Zeng, Huang, \& Dou, 2009; Chen \& Haley, 2010). According to the China Internet Network Information Center (CNNIC), the total number of "netizens" had reached 485 million within a population of 1.3 billion people, and the number of SNS users had reached 230 million in July 2011 (Zhang, 2011). Furthermore, iUserTracker, a user online behavior measurement system launched by iResearch, reported that the number of social networking services had reached 410 million in second quarter 2012, with a year-by-year growth rate of $9.0 \%$ and over $93 \%$ user penetration (iResearch report, 2012). They believe that social networking services have become one of the most 
frequently used services among Chinese Internet users. Moreover, Chinese society has changed dramatically within the past 30 years (Chen \& Haley, 2010), and one distinctive indicator of such societal change in people's lives is the shift in value systems, which can be explained by how people use SNS.

To gain deeper insight into Chinese SNS, it is necessary to explore the current situation of SNS in China, as well as the main users of these SNS. In this research, the first objective focuses on understanding Chinese SNS and their characteristics. The second objective is to explore in detail the characteristics of SNS adoption, especially for the young Chinese generation, which is one of the most active user segments, accounting for approximately 90 percent of those aged between 16 and 30 years (Yanqiu, 2011). Understanding which factors influence online social networking site use will explain users' underling adoption factors, based on the types of involvement toward SNS. However, little research exists in the types of involvement as variables to measure user behavior in relation to the intensity of SNS use. Understanding young Chinese people's involvement in SNS and the relationships between the types of involvement and intensity of SNS use will help to explain and fill the gap from previous research based on some of the underlying adoption factors of SNS in China.

\section{Literature Review}

\subsection{Definition of Social Network}

The network approach can be explained by sociology, anthropology and role theory. First, sociology emphasizes patterns of interaction and communication as the key to understanding social life. Second, in Anthropology, exchange theory emphasizes the content of relationships joining individuals. Finally, role theory defines organizations as "fish nets" of interrelated offices. Furthermore, the social network approach views organizations in society as a system of objects (e.g., people, groups, organization) joined by a variety of relationships (Tichy, Tushman \& Fombrun, 2012). An important characteristic of SNS is that they enable users to make their social networks visible and build connections among individuals (Shi, Lee, Cheung \& Chen, 2010). Social networks exist in a cyber space, thereby allowing individuals to build their profiles and share texts, images, photos, videos, blogs and links with other website members; in fact, they are currently the world's fastest growing personal networking tools (Lin \& Lu, 2011; Sledgianowsky \& Kulviwat, 2009). Boyd and Ellison (2008) define social network sites as web-based services that allow individuals to construct public or semi-public profiles so that users can share connections, view and traverse their connections within a system.

\subsection{Social Network Sites in China and Relevant Literatures}

The Chinese government maintains relatively strict control over information flows on the Internet and some popular social network sites, such as Facebook, which is not available in mainland China (Chen \& Haley, 2010). Even though some popular international social networking sites such as Facebook, Myspace, Twitter and others are not accessible, young Chinese people have alternatives in China's versions of Facebook, Twitter and You Tube such as Renren, Kaisin001, and many others that are available (Yanqiu, 2011). The various Chinese social network sites established since 2007 and China's top social networks sites are Qzone (Tencent), Renren, Pengyou, SinaWeibo, Kaixin001, and 51.com,among others (Appendix 1). Qzone is China's largest social network, with 637 million active users for Tencent's QQ Messenger, and Renren is China's leading real-name social network, which is currently setting the gold standard for SNS in China (Techrice, 2011). In terms of segmentation, Renren is most popular with university students (Yanqiu, 2011). In 2005, Renren was initially a clone of Facebook called Xiaonei (校內); however, since 2009, the site's name was switched to Renren, as well as its strategy with the aim to target college students as the main users, just as Facebook was before opening the site to the general public. Chinese SNS can be divided into several categories in terms of different target groups with its orientations. Such types are as follows: college student-oriented, entertainment-oriented, businessoriented, and dating or marriage matching-oriented (Zhong, 2010). Also, unlike Facebook, a handful of social networks have attracted segmented audiences, ranging from upscale urban youth to university students and migrant workers (The China Business Review, 2011).

In recent years, researchers have conducted comparison studies based on cultural differences and motivations of SNS use among China, Korea and the United States (Ji, Hwangbo, Yi, Rau, Fang \& Ling, 2010; Kwon \& Kim, 2011; Lee Y, 2011). Moreover, Yanjqui (2011) studied political issues shared in a leading domestic SNS site in China and concluded that SNS creates an alternative community space for political discussions that have never existed in the mass media before. Business models of Chinese SNS (Zhong, 2010) and campus SNS in China have been explored by using an extended TAM model (Hou, Fan, Lee \& Suh, 2009). Also, the relationships among the big five personality factors, self-esteem, narcissism and sensation seeking have been examined via Chinese university students' SNS use (Wang, Jackson, Zhang \& Su, 2012). Lin and Lu(2011) explored factors affecting users' behavior of continuously joining SNS by applying network externalities and motivation theory 
by using structural equation modeling(SEM): enjoyment, the number of peers, and usefulness were identified as important influential factors for continued intention to use SNS.

The previous studies examined the relationship between students' demographic characteristics and SNS experiences among SNS users and non-users. Results showed no significant relationship between the two variables (Hargittai, 2007). The actual usage of SNS examined was based on the hedonic perspective, such as perceived trust, playfulness, critical mass, ease of use, usefulness and adoption intention (Sledgianowski \& Kulviwat, 2009). The adoption and non-adoption factors of social network sites for Singapore's working adults were identified (Lin, Chiu \& Lim, 2011). Cheung, Chiu and Lee (2011) explained why students use SNS (Facebook) by social influence theory, the gratifications paradigm and social presence theory.

Online social networking site netizens use SNS for many purposes. Social networking sites typically provide users with a profile space, facilities for uploading content (e.g., photos, music), messaging in various forms and the ability to make connections with other people (Joinson, 2008). In addition, SNS give individuals a venue to identify with others and gain a sense of belonging, such as connecting with family, friends and society (Vanlenzuela, Park \& Kee, 2009). For the young generation, users spend a significant amount of time on selected social network sites and have relatively positive attitudes toward those sites (Chen \& Haley, 2010). A previous study identified the intensity of SNS use. From this study, it was found that Facebook intensity suggested Facebook use as important for bonding social capital; specifically, positive relationships between life satisfaction, social trust, and participation in civic and political activities among college students were identified. Yet, associations between Facebook variables and social capital were small (Ellion, Steinfield \& Lampe, 2007; Valenzuela, Park \& Kee, 2009).Understanding users' SNS adoption factors can be explained by gender and age (Mantsumitrchai, Park \& Chiu, 2012).Also, the popularity of social networking has resulted in a significant decrease in time spent elsewhere online (Chiu, Lin \& Silverman, 2012), A Boston Consulting Group study found that Chinese Internet users are online for an average of 2.7 hours per day, considerably more than other developing countries, and more on par with usage patterns in Japan and the United States (The China Business Review, 2011).

\section{Hypostheses and Research Design}

\subsection{Hypotheses}

\subsubsection{Involvement}

In previous research, many of the different definitions of involvement, such as involvement in advertisements, products, purchases and brands have been identified; the reasons for such diverse definitions and measures of involvement are perhaps due to the different applications of the term "involvement." There are three categories in which to classify involvement, such as personal, physical and situational (Zachkowsky, 1985). The important characteristic of SNS is that they enable users to experience an amount of involvement with social networks and build connections among individuals. This research tries to identify the three different categories of involvement in order to explain the underlying factors involving the relationship between an individual's involvement and the intensity of SNS use.

H1: There are relationships between the intensity of SNS use and the types of involvement (personal, physical, and situational).

\subsubsection{Personal Involvement}

According to Zachkowsky (1985), personal involvement basically concerns inherent interests, values, or needs that motivate one toward an object; in other words, when an individual feels that a system is useful, he or she will think positively about it. Thus, the usefulness of a system has great influence and is positively related to the adoption of information technology (Lin \& Lu, 2011). The perceived usefulness of SNS affects positive intentions to use them (Kang \& Lee, 2010). Usefulness, such as the benefits of SNS use interact with the society, community and events, and trends for SNS use were found among females and young people (Mantsumitrchai, Park \& Chiu, 2012). Such usefulness has been considered as important in determining an individual's acceptance and usage of information technology (Sledgianowski \& Kulviwat, 2009).

H2a: Personal involvement in usefulness positively influences the intensity of SNS use.

For SNS use, activities such as sending and receiving messages, finding people, posting and sharing pictures, viewing profiles, chatting and joining groups were identified, and users liked to share photos and videos on SNS; in particular, females and younger generations engaged much more actively in these activities (Joinson, 2008; Mantsumitrchai, Park \& Chiu, 2012;Lin \& Lu, 2011; Boyd \& Ellison, 2008). 
H2b: Personal involvement in usage positively influences the intensity of SNS use.

\subsubsection{Physical Involvement}

The definition of physical involvement concerns the characteristics of the object that cause differentiation and increase interest (Zachkowsky, 1985). Trust represents a willingness to be placed in a position of vulnerability, based on having positive expectations of another party's future behavior (Zhou, Lu \& Liu, 2010). Trust in or reliability of SNS is considered to be another important physical factor to increase the rate of SNS adoption (Mantsumitrchai, Park \& Chiu, 2012), even though users' perceived risks of using SNS are low. Social network sites have privacy control settings built into the profile options, which enable users to choose who can view and add content to their personal websites, and perceived trust is a significant predictor of intent for SNS use (Sledgianowski \& Kulviwat, 2009).

H3: Physical involvement in trust positively influences the intensity of SNS use.

\subsubsection{Situational Involvement}

Situational involvement is something that temporarily increases relevance or interest toward an object, which refers to how an individual reacts in different situations upon evaluation (Zachkowsky, 1985). Females and younger people are more likely to show their personal information only to their friends and relatives (Mantsumitrchai, Park \& Chiu, 2012). Such a characteristic on SNS, relevant to the relationships among people, can influence the intensity of SNS use.

H4: Situational involvement in relationships positively influences the intensity of SNS use.

\subsubsection{Intensity of SNS Use}

Valenzuela, Park and Kee (2009) used an intensity measurement scale as a dependent variable, which was adapted and modified from Ellison, Steinfield and Lampe (2007).The scale was based on level of agreement with several statements related to users' emotional attachment to sites. In this research, three items from questionnaires related to attachment were used to measure intensity: "I feel I am part of the SNS community"; "I am proud to tell people I am on SNS"; and, "Using SNS is part of my daily activity, and I will keep on using SNSs," were added to increase the validity of the questionnaires. The categories used $1=$ strongly disagree to $5=$ strongly agree Likert scales.

\subsection{Research Design}

Stage 1: Qualitative Method

To understand which factors motivate people to use social network sites by level of involvement, this research used a questionnaire from previous research (Mantsumitrchai, Park \& Chiu, 2012; Lin \& Lu, 2011). The research questionnaire had items that were modified and deleted in order to fit this study by using a pretest on 12 Chinese students currently studying at Keimyung University in Daegu, Korea. This pretest helped identify some of the factors that would be relevant to characteristics of young Chinese people in mainland China. Some demographic factors, such as income level and behavioral factors in the number of years of SNS use, along with the names of social network sites commonly used in China and intensity factors, were identified. In order to recognize a relationship between the involvement factors and the intensity in social network site use, the intensity measurement items -"I'm proud to tell people I am using SNS"; "Using social networks is part of my daily activity": and "I feel I am part of the SNS community" (Valenzuela, Park \& Kee, 2009) - were adopted and modified. In addition, the item, "I will keep on using SNSs," was added to measure intensity. Even though previous research questionnaires have been based on targeted specific social network sites, such as Facebook users, the pretest of the adopted and modified questionnaire for this research made the instrument appropriate for use. Based on previous studies, there are many reasons why people use SNS, but for this study, after the pretest, 26 questions were used to measure underlying factors, and four questions were asked to measure the intensity of SNS use.

Due to the language barrier, at first the survey was created in Korean and was then translated into Chinese by the parallel translation method. The translation had been done by second- and third-generation Chinese and Korean bilingual students from S University and a professor from D University in Korea. These translated surveys were used for the pretest for this study, as well. The parallel translation means that more than two translators were used for the back translation; the results were compared, and differences were discussed (Cateora, Gilly\& Graham, 2009).

Stage 2. Quantitative Method

The purpose of this research was to target Chinese SNS users. Surveys were collected from mainland China. The 
26 questions, and four questions to measure intensity of use, using a 5-point Likert scale, and other demographic and behavioral questions were finalized in Chinese. Due to the distance barrier; data were collected by the O Research Company in Beijing. Two hundred data were collected between October 15 to 21, 2012 for one week, and the main target sample were university students who studied in the Beijing area. The most representative population of this study consisted of university students who using social network sites. The data were delivered in Excel format via email for analysis. For this research, the SPSS statistics version 20 was used in the analysis.

\section{Analysis and Results}

There were two hundred students who participated in the survey. By gender, 63 percent of the participants were female, and 65 percent of the respondents were between 20-23 years old. The majority of the participants were undergraduate students $(\mathrm{n}=141,70.5 \%)$. Approximately $52 \%$ of the participants had no income. Eighty-eight percent of the respondents had been using social network sites (SNS) recently. A total of $75.5 \%$ of users reported spending less than two hours per day on SNS, and 11.5\% reported spending more than 3 hours per day on SNS. Additionally, nearly $67 \%$ of the participants reported using SNS for less than three years. Most of the SNS respondents used were Renren, QQ(Qzone) and SinaSpace. Table 1 provides a profile of the respondents for this study.

Table 1. Demographic information of respondents and their SNS use

\begin{tabular}{|c|c|c|c|}
\hline & Frequency & Percent & Cumulative Percent \\
\hline \multicolumn{4}{|l|}{ Gender } \\
\hline Male & 74 & 37.0 & 37.0 \\
\hline Female & 126 & 63.0 & 63.0 \\
\hline Total & 200 & 100.0 & \\
\hline \multicolumn{4}{|l|}{ Age } \\
\hline Less than 19 & 6 & 3.0 & 3.0 \\
\hline $20-23$ & 131 & 65.5 & 68.5 \\
\hline Above 23 & 63 & 31.5 & 100.0 \\
\hline Total & 200 & 100.0 & \\
\hline \multicolumn{4}{|l|}{ Education } \\
\hline High school & 13 & 6.5 & 6.5 \\
\hline Undergraduate & 141 & 70.5 & 77.0 \\
\hline Graduate & 29 & 14.5 & 91.5 \\
\hline Ph.D. & 2 & 1.0 & 92.5 \\
\hline Missing & 15 & 7.5 & 100.0 \\
\hline \multicolumn{4}{|c|}{ Income per month (Chinese yuen) } \\
\hline Less than 1,500 & 34 & 17.0 & 17.0 \\
\hline $1,501-3,000$ & 23 & 11.5 & 28.5 \\
\hline $3,001-5,000$ & 22 & 11.0 & 39.5 \\
\hline $5,001-8,000$ & 11 & 5.5 & 45.0 \\
\hline More than 8,000 & 6 & 3.0 & 48.0 \\
\hline Have no income & 104 & 52.0 & 100.0 \\
\hline Total & 200 & 100.0 & \\
\hline \multicolumn{4}{|c|}{ Have you been using SNS recently? } \\
\hline Yes & 176 & 88.0 & 88.0 \\
\hline No & 24 & 12.0 & 100.0 \\
\hline Total & 200 & 100.0 & \\
\hline \multicolumn{4}{|c|}{ How much time do you spend on SNS per day on average? } \\
\hline$<30$ minutes & 58 & 29.0 & 29.0 \\
\hline 30 mins-1 hr & 46 & 23.0 & 52.0 \\
\hline $1-2 \mathrm{hrs}$ & 47 & 23.5 & 75.5 \\
\hline
\end{tabular}




\begin{tabular}{lccc}
\hline $2-3$ hrs & 26 & 13.0 & 88.5 \\
More than 3 hrs & 23 & 11.5 & 100.0 \\
Total & 200 & & \\
How many friends do you have on SNS? & & \\
Less than 49 & 46 & 23.0 & 23.0 \\
$50-99$ & 31 & 15.5 & 38.5 \\
$100-299$ & 63 & 31.5 & 70.0 \\
$300-399$ & 26 & 13.0 & 83.0 \\
400-499 & 12 & 6.0 & 89.0 \\
More than 500 & 22 & 11.0 & 100.0 \\
Total & 200 & & \\
How long have you been using & SNS? & & \\
$<6$ months & 29 & 14.5 & 14.5 \\
6-12 months & 13 & 6.5 & 21.0 \\
1-3 years & 92 & 46.0 & 67.0 \\
4-6 years & 52 & 26.0 & 93.0 \\
More than 7 years & 14 & 7.0 & 100.0 \\
Total & 200 & & \\
The SNS most used by respondents & & \\
Sina Space & 53 & 26.5 & 26.5 \\
Renren & 73 & 36.5 & 63.0 \\
Kaixin & 5 & 2.5 & 65.5 \\
QQ & 61 & 30.5 & 96.0 \\
Douban & 4 & 2.0 & 98.0 \\
Kakaotalk & 2 & 1.0 & 99.0 \\
Pengyou & 0 & 0 & 100.0 \\
Other & 2 & 1.0 & \\
Total & 200 & & \\
\hline
\end{tabular}

\subsection{Reliability of Measures}

The reliability test was used to ensure the degree of consistency among the measures for all 26 questions. Cronbach's alpha for the reliability test was .961 (Table 2). For the internal consistency evaluation, the corrected item to the total correlation for each of the 26 items was above .30 , indicating the reliability for each construct. Thus, the reliability measure met the requirement (see Hair et al., 1998). Hotelling's T-square (Table 3) showed a significant level with the calculated F-value of 7.80. Thus, the set of variables met the fundamental requirements for the factor analysis.

Table 2. Result in reliability statistics

\begin{tabular}{ccc}
\hline Cronbach's Alpha & Cronbach's Alpha Based on Standardized Items & N of Items \\
\hline .961 & .962 & 26 \\
\hline
\end{tabular}

Table 3. Hotelling's T-squared test

\begin{tabular}{ccccc}
\hline Hotelling's T-Squared & F & df1 & df2 & Sig \\
\hline 221.838 & 7.803 & 25 & 175 & .000 \\
\hline
\end{tabular}

\subsection{Factor Analysis}

Factor analysis with varimax rotation as an extraction was used to identify the factors. The Kaiser-Meyer-Olkin 
Measure of Sampling Adequacy (KMO) and Bartlett's Test of Sphericity showed statistical significance at the .01 level. Following Hair's (1998) suggestion, the cutoff point of at least .60 was used for the factor loadings. The result indicated four factors with an eigenvalue greater than 1 (see Table 4). The entire explanation of all four factors was 67.82 percent.

The first factor, personal involvement in usefulness, consisted of eleven items with an eigenvalue of 8.612, which accounted for 33.12 percent of the total variance. The second factor, physical involvement in trust, included three items that accounted for 13.47 percent of the variance. The third factor, situational involvement (relationships), contained four items, contributing to 11.42 percent of the variance. The last factor, personal involvement (usage), consisted of two items, which contributed 9.81 percent to the total variance explained. Table 5 shows the results of the means and standard deviations for the factors and their items

Table 4. Factor analysis results

\begin{tabular}{|c|c|c|c|c|}
\hline & F1 & F2 & F3 & F4 \\
\hline \multicolumn{5}{|l|}{ 1. Personal Involvement (Usefulness) } \\
\hline 1. Using SNS is entertaining. & .68 & & & \\
\hline 2. I will use SNS if my family and relatives are using them. & .69 & & & \\
\hline 3. SNS is a good way to keep in touch with friends. & .62 & & & \\
\hline $\begin{array}{l}\text { 4. It is interesting to check others' status and information } \\
\text { through SNS. }\end{array}$ & .71 & & & \\
\hline $\begin{array}{l}\text { 5. SNS are a form of interaction with society, the } \\
\text { community, and events. }\end{array}$ & .78 & & & \\
\hline $\begin{array}{l}\text { 6. SNS let me connect with my family, friends and } \\
\text { relatives. }\end{array}$ & .77 & & & \\
\hline 7. SNS are useful. & .80 & & & \\
\hline 8. SNS are a way to express myself. & .71 & & & \\
\hline 9. I enjoy chatting with people through SNS. & .79 & & & \\
\hline 10. It is a trend to use SNS. & .83 & & & \\
\hline 11. I will use SNS if my friends are using them. & .78 & & & \\
\hline \multicolumn{5}{|l|}{ 2: Physical Involvement(Trust) } \\
\hline 1. I am willing to share personal information on SNS. & & .61 & & \\
\hline 2. Using SNS is safe and secure. & & .79 & & \\
\hline 3. People using SNS are trustworthy. & & .62 & & \\
\hline \multicolumn{5}{|l|}{ 3: Situational Involvement (Relationships) } \\
\hline $\begin{array}{l}\text { 1. I like face-to-face communication rather than using the } \\
\text { Internet. }\end{array}$ & & & .74 & \\
\hline $\begin{array}{l}\text { 2. I prefer to show my personal information only to my } \\
\text { friends. }\end{array}$ & & & .63 & \\
\hline $\begin{array}{l}\text { 3. I prefer to show my personal information only with to } \\
\text { relatives. }\end{array}$ & & & .66 & \\
\hline 4. $\quad$ SNS can harm relationships. (couples/friends) & & & .67 & \\
\hline \multicolumn{5}{|l|}{ 4: Personal Involvement (Usage) } \\
\hline 1. I like sharing photos through SNS. & & & & .68 \\
\hline 2. I like sharing videos through SNS. & & & & .66 \\
\hline Eigenvalues & 8.16 & 3.50 & 2.96 & 2.55 \\
\hline$\%$ variance & 33.12 & 13.47 & 11.42 & 9.81 \\
\hline Cumulative variance & 33.12 & 46.59 & 58.01 & 67.83 \\
\hline Cronbach Alphas & .958 & .960 & .961 & .959 \\
\hline
\end{tabular}


Table 5. Means and standard deviations for the factors and items $(n=200)$

\begin{tabular}{|c|c|c|}
\hline Factors & Mean & S.D. \\
\hline Usefulness (Factor 1)-Independent Variables & 3.46 & $.917($ Cronbach's alpha $=.96)$ \\
\hline Using SNS is entertaining. & 3.42 & 1.1 \\
\hline I will use SNS if my family and relatives are using them. & 3.57 & 1.12 \\
\hline SNS is a good way to keep in touch with friends. & 3.25 & 1.17 \\
\hline It is interesting to check others' status and information through SNS. & 3.59 & 1.1 \\
\hline SNS are a form of interaction with society, the community, and events. & 3.53 & 1.07 \\
\hline SNS lets me connect with my family, friends and relatives. & 3.42 & 1.11 \\
\hline SNS are useful. & 3.43 & 1.04 \\
\hline SNS are a way to express myself. & 3.42 & 1.01 \\
\hline I enjoy chatting with people through SNS. & 3.37 & 1.05 \\
\hline It is a trend to use SNS. & 3.64 & 1.12 \\
\hline I will use SNS if my friends are using them. & 3.51 & 1.08 \\
\hline Trust (Factor 2) & 2.79 & $.90($ Cronbach's alpha $=.74)$ \\
\hline I am willing to share personal information on SNS. & 2.85 & 1.13 \\
\hline Using SNS is safe and secure. & 2.66 & 1.1 \\
\hline People using SNS are trustworthy. & 2.89 & 1.08 \\
\hline Relationship (Factor 3) & 3.35 & 0.87 \\
\hline \multicolumn{3}{|l|}{$($ Cronbach's alpha $=.76)$} \\
\hline I like face-to-face communication rather than using the Internet. & 3.31 & 1.12 \\
\hline I prefer to show my personal information only to my friends. & 3.64 & 1.18 \\
\hline I prefer to show my personal information only to my relatives. & 3.32 & 1.18 \\
\hline SNS can harm relationship. (couples/friends) & 3.16 & 1.1 \\
\hline Usage (Factor 4) & 3.22 & 1.09 \\
\hline \multicolumn{3}{|l|}{$($ Cronbach's alpha $=.79)$} \\
\hline I like sharing photos through SNS. & 3.21 & 1.17 \\
\hline I like sharing videos through SNS. & 3.16 & 1.15 \\
\hline tensity of Social Network Site Use (Dependent Variables) & 3.31 & $.94($ Cronbach's alpha $=.88)$ \\
\hline I am proud to tell people I am on SNS. & 2.96 & 1.02 \\
\hline Using SNS is part of my daily activity. & 3.39 & 1.12 \\
\hline I will keep on using SNS. & 3.54 & 1.14 \\
\hline I feel I am part of the SNS community. & 3.35 & 1.11 \\
\hline
\end{tabular}

Note: A value of "5" indicates "strongly agree," and a value of" 1 " indicates "strongly disagree" on Likert scales.

\subsection{Correlation}

Correlations were used to test the relationship between the dependent variable (intensity of SNS use) and the independent variables, which were the four factors. Pearson correlations showed that there were significant correlations between the intensity of SNS use and all of the four factors at the .01 level. Among the four factors, the findings show that personal involvement in usefulness, the first factor, had the strongest correlation (cor=.933) with the intensity of SNS use. The second strongest correlation (cor $=.719)$ with the intensity of SNS use was personal involvement in usage, which was the fourth factor identified by the factor analysis. In summary, the intensity of SNS use had significant relationships with all types of involvement. Thus, the first hypothesis (H1) was supported. Table 6 shows the correlation results. 
Table 6. Pearson correlations

\begin{tabular}{lccccc}
\hline & Intensity & Usefulness & Trust & Relationship & Useful \\
\hline Intensity & 1 & $.933^{* *}$ & $.703^{* *}$ & $.592^{* *}$ & $.719^{* *}$ \\
Usefulness & $.933^{* *}$ & 1 & $.668^{* *}$ & $.607^{* *}$ & $.724^{* *}$ \\
Trust & $.703^{* *}$ & $.668^{* *}$ & 1 & $.402^{* *}$ & $.587^{* *}$ \\
Relationship & $.592^{* *}$ & $.607^{* *}$ & $.402^{* *}$ & 1 & $.519^{* *}$ \\
Usage & $.719^{* *}$ & $.724^{* *}$ & $.587^{* *}$ & $.519^{* *}$ & 1 \\
\hline
\end{tabular}

** Correlation is significant at the 0.01 level (2-tailed)

\subsection{Regression Analysis}

To test all of the hypotheses, regression analysis was performed. The criterion variable was the intensity of SNS use, and the predictive variables were all of the four factors: personal involvement in usefulness and usage, physical involvement in trust, and situation involvement in relationships.

An ANOVA indicated that the model as a whole (which included two variables) was significant ( $\mathrm{F}=374.94, \mathrm{p}$ $<.01)$. The regression analysis showed that only two independent variables, usefulness and trust, were significant predictor variables with an $\mathrm{R}$ square of .885 . The regression coefficient of the first independent variable, usefulness, was .803 , and the coefficient for the second independent variable, trust, was .139.

In conclusion, the two hypotheses, $\mathrm{H} 2 \mathrm{a}$ and $\mathrm{H} 3$, were supported. Personal involvement in usefulness and physical involvement (trust) influenced the intensity of SNS use. Two hypotheses, H2b and H4, were rejected. Personal involvement in usage and situational involvement in relationships were not significant predictor variables. Table 7 shows the results of the regression model. Table 8 summarizes the hypothesis testing.

Table 7. Regressions predicting the intensity of SNS use from personal involvement, physical involvement, and situational involvement

\begin{tabular}{lccc}
\hline Independent Variables & Unstandardized Coefficient (Beta) & $\mathrm{t}$ & Sig. \\
\hline (Constant) & -0.135 & -1.327 & 0.186 \\
Usefulness & 0.803 & 18.59 & 0 \\
Trust & 0.139 & 3.987 & 0 \\
Relationship & 0.036 & 1.066 & 0.288 \\
Usage & 0.049 & 1.563 & 0.12 \\
$\mathrm{~N}=200$ & R square $=.885$ & & \\
& Adj. R square $=.883$ & & \\
\hline
\end{tabular}

Dependent Variable: Intensity of SNS use

Table 8 . Summary of hypothesis testing

\begin{tabular}{lc}
\hline Hypotheses & Results \\
\hline H1: There were relationships between the intensity of SNS use and the & Supported \\
types of involvement (personal, physical, and situation). & \\
H2a: Personal involvement in usefulness positively Influences the & Supported \\
intensity of SNS use. & \\
H2b: Personal involvement in usage positively influences the intensity & Not supported \\
of SNS use. & \\
$\begin{array}{l}\text { H3: Physical involvement in trust positively influences the intensity of } \\
\text { SNS use. }\end{array}$ & Supported \\
$\begin{array}{l}\text { H4: Situational involvement in relationships positively Influences the } \\
\text { intensity of SNS use. }\end{array}$ & Not supported \\
\hline
\end{tabular}




\section{Discussion}

China has been the fastest-growing market for social network sites for the past few years and will continue to grow. Understanding the Chinese people's perceived usefulness of SNS use will provide insightful ideas about the behaviors of users and perceptions toward SNS in China. Social networking services have become one of the most frequently used services among Chinese Internet users, as they are developing their personal networks through social networking sites (SNS). The underlying adoption factors of users, based on the types of involvement and relationships between the intensity of SNS use, are explored in this paper. The empirical results demonstrate that the intensity of SNS use is significantly affected by the types of involvement. The relationships between personal, physical, situational involvement and intensity of SNS use were significantly correlated, but the regression results identified that only personal involvement in usefulness and physical involvement in trust were the influencing factors of the intensity of SNS use. The factor of personal involvement in usage shows an association with intensity of SNS use, but it was not statically significant in terms of explaining the factors contributing to the intensity of SNS use in China. Even though sharing photos and videos are represented as good usage reasoning for SNS, such activities do not significantly influence intensity. Physical involvement in trust ("Information shared on SNS is reliable"; "I am willing to share personal information on SNS"; "Using SNS is safe and secure"; and, "People using SNS are trustworthy") is an important factor to explain the intensity of SNS use, but the results show that users in general do not think that social network sites are reliable or trustworthy. From the results, users do not strongly trust information sharing on SNS and do not think that SNS are safe and secure. Nevertheless, users are willing to use social networks sites because of their usefulness. It is quite interesting to find a relationship between the intensity of SNS use and trust. Also, the situational involvement factor of relationship did not significantly influence intensity. Users prefer to show their own personal information only to friends, and relatives, thereby explaining why users prefer face-to-face communication to using the Internet. Users also think that SNS can harm relationships with couples and friends. If users do not have strong connections with friends and relatives through SNS, it possibly may decrease their intensity of SNS use.

Overall, the results suggest that personal involvement in SNS usefulness and physical involvement in trust are the most important factors to explain the intensity of SNS use among young Chinese people. Even though trust in SNS is not strongly shown in this research, Chinese users tend to feel that their inherent interests and values, which are reflected in SNS, motivate them to keep on using SNS. Identifying with others and gaining a sense of enjoyment, social interaction, connecting with family, friends, and society, and gaining insight into the circumstances of others are all reasons that can motivate people to use SNS (Valenzuela, Park \& KEE, 2009). This study extends the previous literature about the relationship between adoption factors by using types of involvement and intensity of SNS use to explain the adoption behavior of Chinese people. Understanding the most vibrant market segment in China will lead to more international SNS enterprises that will be able to gain more access to the Chinese market. For the limitations of this research, the study mainly uses university students, who are a homogenous group; thus, the findings of this study may not be generalizable to the Chinese population as a whole.

For future research, conducting surveys from other cities in China will help us have a better understanding of Chinese social network site users' behaviors. Such comparison studies in Beijing, Shanghai and Guangzhou would be interesting, since the top three cities with most users compare to other areas in China (Yanqiu, 2011). And, the meanings of social network sites are relatively broad, since China's social networking landscape is much more diverse in users and purposes; therefore, investigating diverse social network sites or comparing different types of SNS may offer a better understanding of Chinese users.

\section{References}

Ari, S., Davis, L., \& Cindy, C. (2012). China's social-media boom. McKinsey \& Company.

Boyd, D. M., \& Ellison, N. B. (2008). Social network sites: Definition, history, and scholarship. Journal of Computer-Mediated Communication, 13, 210-230. http://dx.doi.org/10.1111/j.1083-6101.2007.00393.x

Cateora, G., \& Graham. (2009). International marketing (14th ed.). McGraw Hill.

Christy, M. K. C., Pui-Yee, C., \& Matthew, K. O. L. (2011). Online social network: Why do students use Facebook? Computers in Human Behavior, 27, 1337-1343. http://dx.doi.org/10.1016/j.chb.2010.07.028

Hair, J., Anderson, R., Tatham, R., \& Black, W. (1998). Multivariate data analysis (5th ed.). Upper Saddle River, NJ, Prentice-Hall.

Hargittai, E. (2007). Whose space? Difference among users and non-users of social network sites. Journal of 
Computer-Mediated Communications, 13, 276-297. http://dx.doi.org/10.1111/j.1083-6101.2007.00396.x

Hargittai, E., \& Litt, E. (2011). The tweet smell of celebrity success: Explaining variation in Twitter adoption among a diverse group of young adults. New Media Society, Sage Publications. http://dx.doi.org/10.1177/1461444811405805

Hou, Fan, Lee., \& Suh. (2009). Determinants affect intention to campus SNS in China. The Korean Society for Quality Management, Fall conference proceeding paper.

Huan, C., \& Eric, H. (2010). The lived meanings of Chinese social network sites (SNSs) among urban white-collar professionals: A story of the happy network. Journal of Interactive Advertising, 11(1), 11-26.

Ji, Hwangbo, Yi, Rau, Fang \& Ling. (2010). The influence of cultural differences on the use of social network services and the formation of social capital. International Journal of Human-Computer Interaction, 26 (11-12), 1100-1121. http://dx.doi.org/10.1080/10447318.2010.516727

Jin-Liang, W., Linda, A. J., Da-Jun, Z., \& Zhi-Qiang, S. (2012). The relationships among the big five personality factors, self-esteem, narcissism, and sensation-seeking to Chinese university students' uses of social networking sites (SNSs). Computers in Human Behavior, 28, 2313-2319. http://dx.doi.org/10.1016/j.chb.2012.07.001

Joinson, A. N. (2008). Looking at, looking up, or keeping up with people? Motives and uses of Facebook. Proceeding paper at Online Social Networks, Florence, Italy.

Kang, \& Lee (2010). Understanding the role of an IT artifact in online service continuance: An extended perspective of user satisfaction. Computers in Human Behavior, 26, 353-364. http://dx.doi.org/10.1016/j.chb.2009.11.006

Kwon, S., \& Kim, T (2012). A comparative study on the national culture of SNS users: Comparison of Korea, China and the U.S. Journal of Information Technology Applications \& Management, 18(4), 131-147.

Lee, Y. (2011). The impact of Chinese cultural dispositions on the SNS eWOM behavior. International Area Studies Review, 15(3), 493-511.

Lin, K., \& Lu, H. (2011). Why people use social networking sites: An empirical study integrating network externalities and motivation theory. Computers in Human Behavior, 27, 1152-1161. http://dx.doi.org/10.1016/j.chb.2010.12.009

Mansumitrchai, S., Choo-Hui, Park., \& Candy, Lim, Chiu. (2012). Factors underlying the adoption of social network: A study of Facebook users in South Korea. International Journal of Business and Management, 7(24), 138-153. http://dx.doi.org/10.5539/ijbm.v7n24p138

Na, S., Matthew, K. O. L., Christy M. K. C., \& Huaping C. (2010). The continuance of online social networks: How to keep people using Facebook? Proceedings of the $43^{\text {rd }}$ Hawaii International Conference on System Sciences.

Nicole, B. E., Charles, S., \& Cliff, L. E. (2007). The benefits of Facebook friends: Social capital and college students use of online social network sites. Journal Computer-Mediated Communication, 12, 1143-1168. http://dx.doi.org/10.1111/j.1083-6101.2007.00367.x

Noel, M. T., Michael, L. T., \& Charles, F. T. (1979). Social network analysis for organizations. Academy of Management Review, 4(4), 507-519.

Sebastián, V., Namsu, P., \& Kerk, F. K. (2009). Is there social capital in a social network site? Facebook use and college students' life satisfaction, trust, and participation. Journal of Computer-Mediated Communication, 14, 875-901. http://dx.doi.org/10.1111/j.1083-6101.2009.01474.x

Sledgianowski, D., \& Kulviwat, S. (2009). Using social network sites: The effects of playfulness, critical mass and trust in a hedonic context. The Journal of Computer Information Systems, 49(4). ProQuest Central Basic.

Techrice. (2012). 'China's top 15 social networks'. Retrieved from http:techrice.com/2011/03/08/chinas-top-social-networks/

The China Business Online Review. (2011). Social media in China: The same, but different. Retrieved from http://www.thomascrampton.com/china/social-media-china-business-review/

Trisha, T. C. L., Vicki, C. H. C., \& Wendy, L. (2011). Factors affecting the adoption of social network sites: Examining four adopter categories of Singapore's working adults. Asian Journal of Communication, 21(3), 


\section{1-242. http://dx.doi.org/10.1080/01292986.2011.559256}

Yanqiu, Z. (2011). Young people and SNS political communication in China: Participatory practices in alternative community-oriented spaces. Communications \& Convergence Review 2011, 3(2), 144-155.

Zaichkowsky, J. L. (1985). Measuring the Involvement Construct. Journal of Consumer Research, 12(December), 341-35. http://dx.doi.org/10.1086/208520

Zhong, Z. (2010). Social Networking Services (SNS) in China. International Journal of e-Business Management, 4(1), 66-69. http://dx.doi.org/10.3316/IJEBM0401066

Zhou, Li., \& Liu. (2010). The effect of flow experience on mobile SNS user's loyalty. Industrial Management \& Data System, 110(6), 930-946. http://dx.doi.org/10.1108/02635571011055126

Appendix

Appendix 1. China's top 15 social networks

\begin{tabular}{|c|c|c|c|c|c|c|}
\hline & & Type & User Demographics & $\begin{array}{l}\text { Active Users } \\
\text { (millions) }\end{array}$ & $\begin{array}{l}\text { Reg. Users } \\
\text { (millions) }\end{array}$ & Alexa CN Rank \\
\hline 1 & 23. $\mathrm{QQ}$ 空间 & Nickname SNS & Teens & $190^{2}$ & $481^{3}$ & $\begin{array}{c}\# 12 \\
\text { (Qzone only est.) }\end{array}$ \\
\hline 2 & RenRen Wrenren & Real-name SNS & Students, white-collars & 951 & $170^{1}$ & $\# 16$ \\
\hline 3 & Pengyou 为腾讯朋友 & Real-name SNS & Students, white-collars & $80^{2}$ & $131^{3}$ & \#36 \\
\hline 4 & Sina Weibo ( $_{\text {新浪微博 }}^{\text {S }}$ & Microblog & White-collars & 65 & 120 & - \\
\hline 5 & 开心网 & Real-name SNS & White-collars & $40^{1}$ & 95 & \#19 \\
\hline 6 & $51 . \mathrm{com} \quad 51 . \mathrm{cm}$. & Real-name SNS & $\begin{array}{l}\text { Lesser-tier cities, rural } \\
\text { users }\end{array}$ & 40 & 178 & $\# 51$ \\
\hline 7 & Douban 五踓douban & Nickname SNS & Urban youth & 20 & 40 & $\# 22$ \\
\hline 8 & $\begin{array}{l}\text { Taomee Toomee淘米 } \\
\text { (Seer, Mole, etc.) }\end{array}$ & $\begin{array}{l}\text { Children's SNS / } \\
\text { Games }\end{array}$ & Children, mothers & $20^{2}$ & 180 & - \\
\hline 9 & Tencent Weibo 腾讯微博 & Microblog & Lesser-tier cities & $20^{2}$ & 100 & - \\
\hline 10 & 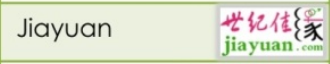 & Dating SNS & White-collars & $11^{2}$ & 30 & \#43 \\
\hline 11 & $\begin{array}{l}\text { Tao Jianghu 淘江湖 } \\
\text { (Taobao) }\end{array}$ & E-commerce SNS & All & $10^{2}$ & $\begin{array}{c}1200 \\
\text { (all Taobao) }\end{array}$ & - \\
\hline 12 & $\begin{array}{l}\text { Bai Shehui } \\
\text { (Sohu) }\end{array}$ & Real-name SNS & White-collars & $5^{2}$ & 30 & - \\
\hline 13 & 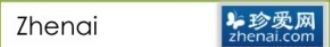 & Dating SNS & White-collars & $3^{2}$ & 26 & $\# 370$ \\
\hline 14 & 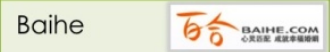 & Dating SNS & White-collars & $2^{2}$ & 23 & $\# 412$ \\
\hline 15 & 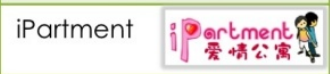 & $\begin{array}{l}\text { Avatar / dating } \\
\text { SNS }\end{array}$ & Urban youth & 12 & 20 & $\# 514$ \\
\hline $\begin{array}{l}1- \\
3- \\
\text { (c) }\end{array}$ & $\begin{array}{l}\text { arch iUserTracker } 2 \text { - TechRice } \\
\text { ent claims these as "actives", b } \\
\text { ice March } 2011\end{array}$ & $\begin{array}{l}\text { Estimate (via reports, } \\
\text { ut TechRice believes t }\end{array}$ & $\begin{array}{l}\text { fic, experts, and guesswork } \\
\text { s closer to registered users }\end{array}$ & & & \\
\hline
\end{tabular}

Source: http://techrice.com/2011/03/08/chinas-top-15-social-networks 